\title{
Thermal decomposition of an agroindustrial waste under inert and oxidizing atmospheres
}

\author{
Thermal decomposition of an agroindustrial waste
}

\author{
[A. Ronda, M. Calero, G. Blázquez, A. Pérez, M.A. Martín-Lara]
}

\begin{abstract}
Thermogravimetric analysis (TG) of the thermal degradation of an agroindustrial waste (AIW), a mix of twophase olive mill solid waste, olive stone, olive tree pruning and the manure of sheep or chicken, was conducted under inert (nitrogen) and oxidizing (air) atmospheres. Non-isothermal conditions were employed at a heating rate of $20^{\circ} \mathrm{C} / \mathrm{min}$ to investigate the effect of type of purge gas (nitrogen or air). The gaseous emissions were analyzed during combustion process, and obtained results agree with other authors from small-scale combustion of agricultural biomass fuels.
\end{abstract}

Keywords-agroindustrial waste, combustion, gaseous compounds, pyrolysis, thermogravimetric analysis.

\section{Introduction}

Over the last 10 years, a high amount of waste are accumulate in lands. Between them, numerous animal organic residues and industrial activity wastes. In this study a mix of some wastes (two-phase olive mill solid waste, olive stone, olive tree prunning and soil sediment solids) was characterized in terms of its physic-chemical properties, which can be useful for its use in pyrolysis and combustion units and to obtain energy. The use of this solid residue is of great economic and social importance for the Mediterranean area, as it accumulates in large amounts during olive oil production. Nowadays, serveral applications for each component of the studied mix have been proposed: as biosorbent of heavy metals from wastewater [1,2], as fuel for heating [3,4], as raw material for activated carbon production [5], as bioethanol production [6], as an amendment for groundwater pollution by MTBU [7], etc. However, any authors have studied a possible application of the mix. In this sense, the study of its thermal degradation is the subject of interest of this work, focussing mainly on the degradation mechanism and emission of gaseous compounds.

A. Ronda, M. Calero, G. Blázquez, A. Pérez, M.A. Martín-Lara line 1: Department of Chemical Engineering. University of Granada line 2: Spain
The correct interpretation of the experimental data obtained by thermogravimetric analysis can provide information about the material composition and kinetics of thermal decomposition (number of processes that is taking place, corresponding kinetic parameters, etc.) in both pyrolytic and oxidative conditions. All it is applied to the design of the pyrolysis or combustion reactors for the generation of chemical compounds or the energy exploitation, respectively.

\section{Experimental}

\section{A. Solid sample}

The studied waste is a mix of two-phase olive mill solid waste, olive stone, olive tree pruning and the manure of sheep or chicken. This mixture is contained in a trench and it is turns daily twice by an automatic system during 9 hours. The temperature of the process is controlled and it is not higher than $60^{\circ} \mathrm{C}$. This waste is produced in an olive industry located in the municipal term of Cazorla (Jaén, Spain).

The ultimate, proximate and biochemical analyses of the AIW are listed in Table 1.

TABLE I. ULTIMATE, PROXIMATE, BIOCHEMICAL ANALYSES AND GROSS CALORIFIC VALUE OF THE AIW

\begin{tabular}{|c|c|c|}
\hline \multirow{4}{*}{$\begin{array}{c}\text { Ultimate } \\
\text { analysis }\end{array}$} & Carbon, \% & 51.49 \\
\cline { 2 - 3 } & Hydrogen, \% & 7.46 \\
\cline { 2 - 3 } & Nitrogen, \% & 1.59 \\
\cline { 2 - 3 } & Oulfur, \% & $<0.1$ \\
\hline \multirow{3}{*}{$\begin{array}{c}\text { Proximate } \\
\text { analysis }\end{array}$} & Volatile matter, \% & 39.36 \\
\cline { 2 - 3 } & Fixed carbon, \% & 69.78 \\
\cline { 2 - 3 } & Ash, \% & 3.834 \\
\hline \multirow{2}{*}{$\begin{array}{c}\text { Biochemical } \\
\text { analysis }\end{array}$} & Hoisture, \% & 21.92 \\
\cline { 2 - 3 } & Etanol-bencene soluble compounds, \% & 5.47 \\
\cline { 2 - 3 } & Lignin and Hollocelulose, \% & 74.23 \\
\hline $\begin{array}{c}\text { Gross } \\
\text { Calorific } \\
\text { Value }\end{array}$ & Calorimetric pump, kcal/kg & 5710.02 \\
\hline
\end{tabular}


The SEM micrograph is shown in Figure 1. The surface features of the waste reveal an irregular and porous morphology, with grooves and large number of steps and kinks on the external surface. Images show the heterogeneity of the waste, which is formed for an assemblage of particles, without regular or fixed shape and size.

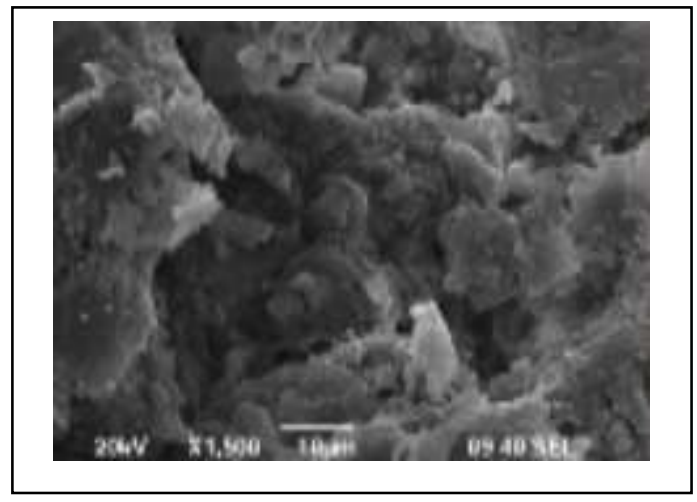

Figure 1. Surface morphology of the solid waste.

\section{B. Thermogravimetric analysis}

Thermogravimetric experiments were performed using a Perkin Elmer thermobalance model STA 6000. A small sample of solid (approximately 40-60 mg) was placed in the thermobalance and, afterwards selected scans were processed (sample was heated at $20^{\circ} \mathrm{C} / \mathrm{min}$ in a flow of nitrogen and air with a final temperature of $800{ }^{\circ} \mathrm{C}$ ).

\section{Results and Discussion}

The TG (Thermogravimetric) curves of AIW at different atmospheres (nitrogen and air) are illustrated in Figure 2.

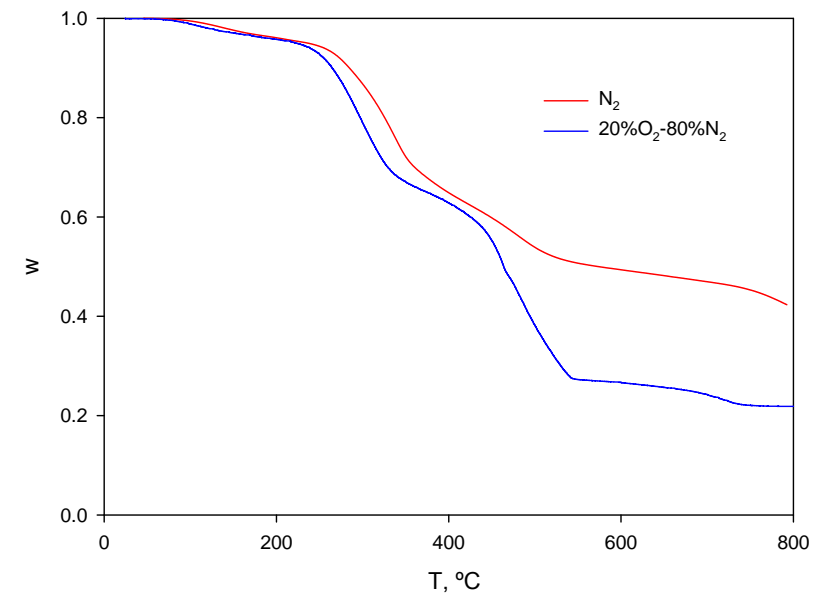

Figure 2. TG curves for the pyrolysis and gasification of AIW at heating rate of $20^{\circ} \mathrm{C} / \mathrm{min}$
Analyzing the results obtained in the present study in inert and oxidizing atmospheres, the weight loss process starts at similar temperatures in both cases. However, at higher temperatures from $450{ }^{\circ} \mathrm{C}$, differences of degradation can be observed for the TG curve in air, due to oxidation reactions.

\section{A. Pyrolysis}

Figure 3 shows the thermogravimetric (TG) and derivative thermogravimetric (DTG) curves under nitrogen atmosphere.

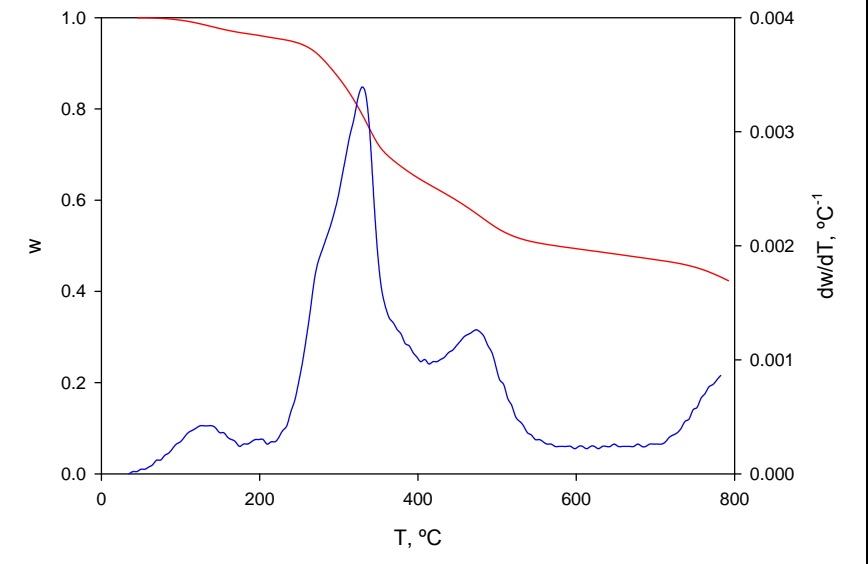

Figure 3. Thermogravimetric (TG) and derivative thermogravimetric (DTG) curves of AIW under nitrogen atmosphere.

The weight loss during thermal degradation in nitrogen occurred continuously until the weight was almost constant. The thermogravimetric curve showed major loss stages between 200 and $400{ }^{\circ} \mathrm{C}$ and between 400 and $550{ }^{\circ} \mathrm{C}$. The weight fraction represents the mass fraction of the solid presented at each temperature respect to initial mass of solid sample and comprises char formed and non-reacted initial solid. The experimental DTG plot shows that the pyrolysis process consisted of four main stages. First, there is an initial small evolution of volatiles on TG that was mainly attributed to the release of water vapor due to drying of the sample. It corresponds to the first peak on the DTG curve. Other peaks on DTG curve observed at higher temperatures can be attributed to genuine pyrolysis process. The second decomposition step in the temperature range of $200-400{ }^{\circ} \mathrm{C}$ could be attributed to decomposition of hemicelluloses. Later, the third stage was mainly attributed to the degradation of the cellulose. Compared to hemicellulose, cellulose pyrolyzed at higher temperature range (about $450^{\circ} \mathrm{C}$ ). Finally, the fourth stage (a peak at the tail of the curve) was mainly attributed to lignin. In contrast to the sharper DTG peak of cellulose, lignin pyrolyzed slowly in a very broad range of temperature (100$800^{\circ} \mathrm{C}$ ) providing a gently sloping baseline to the DTG curve.

\section{B. Gasification}

The TG curves for the air atmosphere (Figure 4) showed similar trends as in the inert atmosphere.

The presence of oxygen likely enhanced the decomposition of AIW at even low temperatures and promoted the 
combustion of char residue. The burning of residual char stage is clearly visible.

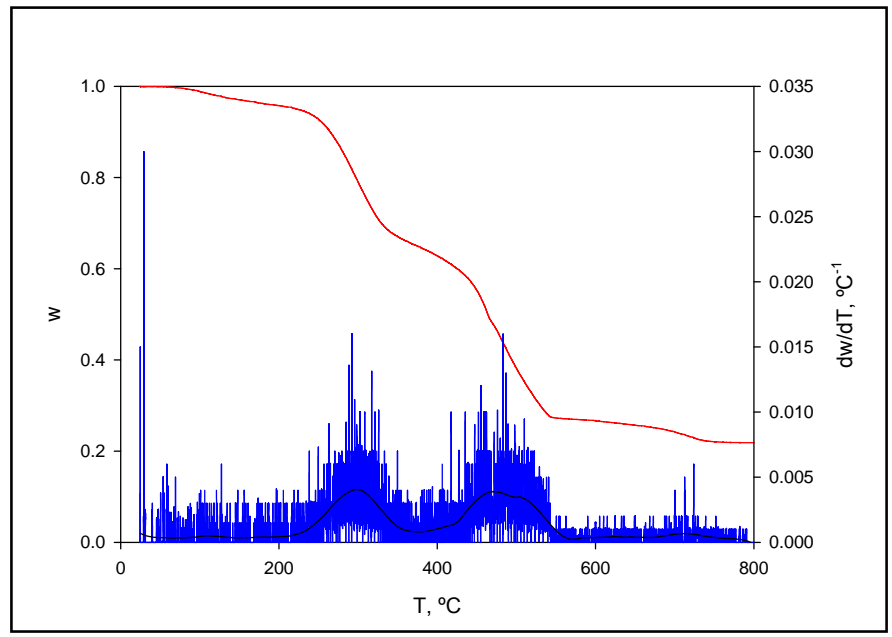

Figure 4. Thermogravimetric (TG) and derivative thermogravimetric (DTG) curves of AIW under air atmosphere.

From the DTG curve, it can be observed that there are two main peaks, with the maximum decomposition rate at $300{ }^{\circ} \mathrm{C}$ and $500{ }^{\circ} \mathrm{C}$ that coincides with the processes observed in pyrolysis. Lastly, a third peak is observed with maximum decomposition rate at $750{ }^{\circ} \mathrm{C}$, leading to a solid residue yield of $22 \mathrm{wt} \%$.

\section{Analysis of gaseous products}

The analysis of the gases gives information about the combustion process. Thus, for example the ratio between $\mathrm{CO} /\left(\mathrm{CO}+\mathrm{CO}_{2}\right)$, change as the reaction occurs, and this value decreases when the oxygen in the environment increases.

A typical spectral output from TG-FTIR of AIW is shown in Figure 5. It can be observed the characteristic peaks of combustion gases and their wavenumbers. The produced gases during the combustion of the waste were mainly carbon dioxide, carbon monoxide, water, methane, mehanol, formaldehyde, ethylene and nitric oxide, similar to obtained for combustion of other agricultural wastes by several authors [8].

Besides, the high concentration of $\mathrm{C}$ obtained in elemental analysis (Table 1) has a positive impact the heating value of the fuel. However, the high content of ashes (Table 1) contributes to particulate matter emissions and to operational problems such as fouling and slagging which may disturb the combustion process, reduce boiler efficiency and lead to higher levels of compounds from an incomplete combustion including carbon monoxide (CO) and some hydrocarbons [8]. Thus, the produced compounds during combustion are related with the characterization of the waste.

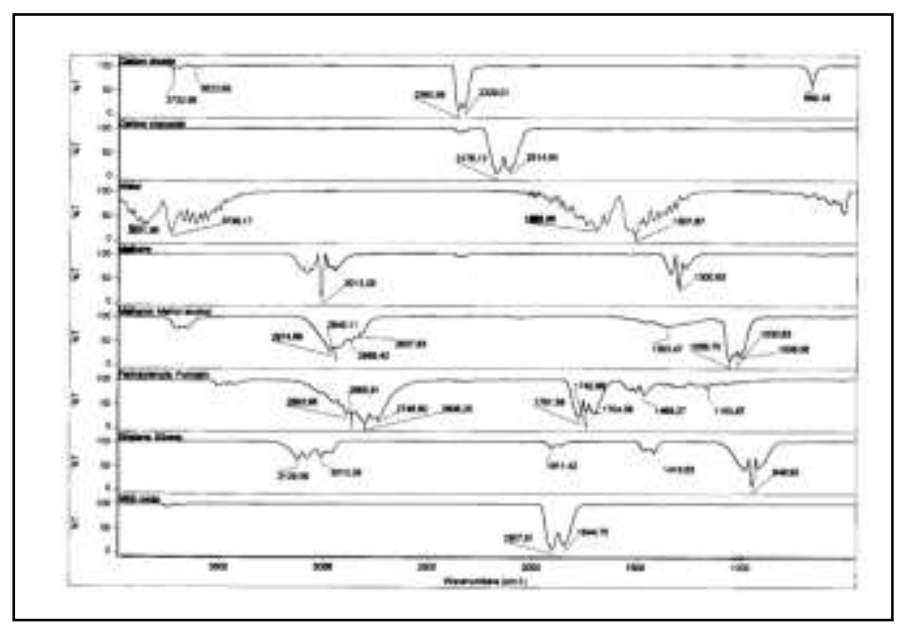

Figure 5. Spectral output from TG-FTIR of AIW.

Figure 6 represents spectral output at several times of the combustion. It is observed that at initial time $(\mathrm{t}=5 \mathrm{~min})$ only $\mathrm{CO}_{2}$ and water were obtained. Oce the sample was consumed and the temperature increased, more compounds were produced. Around time $50 \mathrm{~min}$ the gases emission reached a maximum (all compound were observed in the output). As the combustion progresses, peaks for methane, methanol, formaldehyde, ethylene and nitric oxide were dissapearing, remained mainly carbon monoxide and dioxide. At the end of the reaction $(\mathrm{t}=94 \mathrm{~min})$ only characteristic peaks of carbon dioxide and water were observed. It is also observed that the combustion conditions change during the process, at initial times, the ratio between $\mathrm{CO} /\left(\mathrm{CO}+\mathrm{CO}_{2}\right)$ was higher (meaning a pronounced oxidative pyrolysis), and this ratio decreased with the time, indicating an increase of the oxygen in the environment.

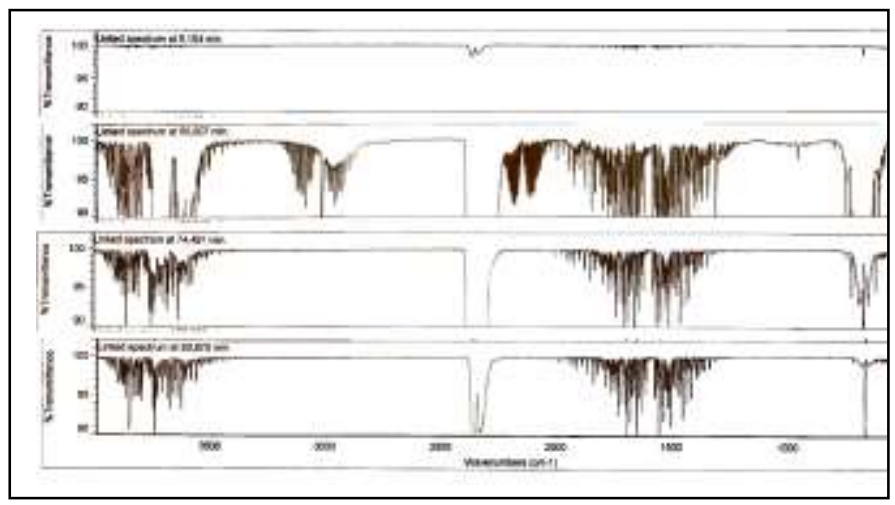

Figure 6. Spectral output from TG-FTIR of AIW at several times of the combustion reaction.

\section{Conclusions}

The pyrolysis and gasification of an agroindustrial waste has been studied. Results showed that the weight loss process started at similar temperatures in inert and oxidizing atmospheres however, at higher temperatures differences of 
degradation can be observed for the TG curve in air, due to oxidation reactions. It was observed two main peaks in the DTG curves, (around $300{ }^{\circ} \mathrm{C}-500{ }^{\circ} \mathrm{C}$ ) that coincided for studied thermal decomposition (under inert and oxidizing atmospheres). The produced gases during the reaction were due to a incomplete combustion and they were related with an the high content of ashes in the waste. During the combustion, the ratio between carbon monoxide and total carbon (monoxide and dioxide) indicated the process conditions and this ratio decreased with the time, indicating the total combustion of the carbon.

\section{Acknowledgment}

The authors are grateful to the Secretaría General de Universidades, Investigación y Tecnología for financial support received (Proyecto de Investigación de Excelencia de la modalidad Motrices y de Innovación 2012 -RNM2390) in the realization of this work.

\section{References}

[1] G. Blázquez, M.A. Martín-Lara, G. Tenorio, M. Calero, "Batch biosorption of lead(II) from aqueous solutions by olive tree pruning waste: Equilibrium, kinetics and thermodynamic study", Chem. Eng. J. vol. 168, pp. 170-177, 2011.

[2] G. Blázquez, M. Calero, A. Ronda, G. Tenorio, M.A. Martin-Lara, "Study of kinetics in the biosorption of lead onto native and chemically treated olive stone", J. Ind. Eng. Chem. vol. 20, pp 2754-2760, 2014.

[3] R. Spinelli, G. Picchi, "Industrial harvesting of olive tree pruning residue for energy biomasa", Bioresour. Technol., vol. 101, pp. 730-735, 2010.

[4] N. Gómez, J.G. Rosas, J. Cara, O. Martínez, J.A. Alburquerque, M.E. Sánchez, M. E, "Slow pyrolysis of relevant biomasses in the Mediterranean basin. Part 1. Effect of temperature on process performance on a pilot scale", J. Clean. Prod., in press.

[5] C. Kütahyali, M. Eral, "Sorption studies of uranium and thorium on activated carbon prepared from olive stones: Kinetic and thermodynamic aspects" J. Nucl. Mater. vol. 396, pp. 251-256, 2010.

[6] I. Ballesteros, M. Ballesteros, C. Cara, F. Sáez, E. Castro, P. Manzanares, M.J. Negro, J.M. Oliva, "Effect of water extraction on sugars recovery from steam exploded olive tree pruning", Bioresour. Technol. vol. 102, pp. 6611-6616, 2011.

[7] J. Fenoll, P. Flores, P. Hellín, J. Hernández, S. Navarro, "Minimization of methabenzthiazuron residues in leaching water using amended soils and photocatalytic treatment with $\mathrm{TiO}_{2}$ and $\mathrm{ZnO}$ ", J. Environm. Sci. vol. 26, pp. 757-764, 2014.

[8] S. Fournel, B. Marcos, S. Godbout, M. Heitz, "Predicting gaseous emissions from small-scale combustion of agricultural biomass fuels", Bioresour. Technol., vol. 179, pp. 165-172, 2014. 